\title{
Usos da teoria dos processos civilizadores no Brasil: análise do estado do conhecimento
}

\section{Uses of the civilizing process theory in Brazil: analysis of the state of knowledge}

\author{
Ana Flávia Braun Vieira \\ Universidade Estadual de Ponta Grossa - UEPG - Ponta Grossa - Brasil \\ ana.braun@yahoo.com.br \\ Miguel Archanjo de Freitas Junior \\ Universidade Estadual de Ponta Grossa - UEPG - Ponta Grossa - Brasil \\ mfreitasir@uepg.br
}

\section{Resumo}

Embora a teoria dos processos civilizadores tenha sido desenvolvida por Norbert Elias na década de 1930, sua apropriação pelos pesquisadores brasileiros ainda é recente. Até 2009 , as produções brasileiras com este referencial seguiam utilizando aspas para citar literalmente 0 autor, sem necessariamente produzir novos conhecimentos a partir dela. Todavia, acredita-se que este cenário esteja se modificado. Diante do crescente interesse dos pesquisadores pela abordagem sociológica de Elias, faz-se necessário identificar o estágio atual de apropriação da teoria dos processos civilizadores. Assim, buscando conhecer a maneira como tem sido utilizada, foi realizado o mapeamento e a análise das produções das Ciências Humanas e Sociais que a adotaram para estudar empiricamente figurações brasileiras. Para tanto, foram empregados os pressupostos das pesquisas sobre o Estado do Conhecimento aliados à Análise de Conteúdo. $O$ acesso às publicações ocorreu por meio da consulta dos termos "processo civilizador", "Elias" e "Brasil" nas bases de dados Scientific Eletronic Library Online (Scielo) e Portal de Periódicos CAPES/MEC. Ao todo, oito foram as produções analisadas, por meio das quais se constatou que a maior parte das pesquisas foram desenvolvidas em instituições de ensino superior da região Sudeste e publicadas em revistas de perspectiva histórica bem avaliadas. Sobre os usos da teoria, a análise demonstrou que os pesquisadores brasileiros têm apresentado avanços em relação às proposições originais de Elias, especialmente no sentido de uma emancipação metodológica em relação ao recorte temporal. No entanto, trata-se ainda de uma posição intermediária, situada entre a citação direta e a produção de novos saberes.

Palavras-chave: teoria dos processos civilizadores, Norbert Elias, estado do conhecimento.

\section{Abstract}

Although the civilizing process theory was developed by Norbert Elias in the 1930s, its appropriation by Brazilians researchers is still recent. Until 2009, Brazilian productions with this framework continued to use quotation marks to cite literally the author, without 
necessarily producing new knowledge from it. However, it is believed that this scenario is changing. In face of the growing interest of researchers on Elias' sociological approach, it is necessary to identify the current stage of appropriation of the civilizing process theory. Thus, aiming to know the way in which it has been used, the mapping and analysis of the productions from Human and Social Sciences that adopted it to study Brazilian figurations empirically was carried out. For this purpose, the assumptions of the research on the State of Knowledge combined with Content Analysis were used. Access to publication occurred by consulting the terms "civilizing process", "Elias" and "Brazil" in the Scientific Eletronic Library Online (SciELO) and CAPES/MEC Journals Portal databases. Altogether, eight were the productions analyzed, through which it was found, through which it was found that most of the research was developed in higher education institutions in the Southeast region and published in well-reviewed historical perspective journals. Regarding the uses of the theory, the analysis showed that Brazilian researchers have made progress in relation to Elias' original propositions, especially in the sense of a methodological emancipation relates the temporal perspective. However, it is still an intermediate position, situated between direct quotations and the production of new knowledge.

Keywords: civilizing process theory, Norbert Elias, state of knowledge.

\section{Introdução}

A teoria dos processos civilizadores foi desenvolvida pelo sociólogo judeu-alemão Norbert Elias (1897-1990) e tem sido adotada em diversas áreas do conhecimento como pressuposto teórico e metodológico na interpretação de fenômenos sociais. Suas formulações iniciais foram publicadas em 1939 e, de acordo com Rojas (1998), trata-se de um marco geral de referência na trajetória intelectual de Elias.

Para desenvolvê-la, o autor pesquisou manuais de etiqueta europeus, publicados entre a Idade Média e o Renascimento. Adotando uma perspectiva comparativa de longa duração, o autor observou que - de maneira interdependente - os patrões de comportamento socialmente aceitáveis (psicogênese) foram alterados ao longo do tempo em consonância com as modificações nas estruturas sociais (sociogênese). Na opinião de Elias, esse conjunto de transformações orientou-se para o estabelecimento de uma conduta "mais estável, diferenciada, uniforme e estável" (Elias, 1993, p. 196) e foi estimulado pela monopolização da força física e da tributação, da crescente estabilidade dos órgãos centrais da sociedade, da progressiva divisão de funções e do aumento da dependência mútua entre os indivíduos.

Dado os paradigmas sociológicos de seu tempo, para estudar os processos civilizadores Elias desenvolveu um conjunto de noções próprias, entre as quais destacamse os conceitos de civilização, figuração e processos sociais (Elias, 2006). A partir desse repertório é possível analisar empiricamente uma série de fenômenos sociogenéticos e psicogenéticos, como a transformação de guerreiros em cortesãos ao longo de vários séculos ou as mudanças no padrão de autorregulação dos motoristas em aproximadamente 3 décadas.

Segundo a Fundação Norbert Elias (2020), pesquisadores de diferentes nacionalidades têm se valido das proposições sociológicas do autor em seus estudos. No caso dos brasileiros, por mais que a teoria tenha sido desenvolvida no início do século $\mathrm{XX}$, as referências ao Elias tornaram-se mais significativas somente a partir da década de 1990 (GEBARA, 2014). No entanto, existe certa dificuldade na aplicação da teoria quando da análise empírica de fenômenos sócio e psicogenéticos (SOUZA, 2009).

Segundo os estudos de Souza (2009) sobre os usos do referencial elisiano na produção do conhecimento sobre os problemas históricos-sociais brasileiros, existem três estágios para a apropriação da teoria nas pesquisas acadêmicos: 1) estudo flutuante, no 
qual busca-se conhecer a complexidade das obras publicadas do autor; 2) aprofundamento dos conceitos, no qual a realidade é iluminada pelas categorias analíticas; 3) aplicação da teoria, na qual os conceitos são colocados em movimento interpretativo para a análise de determinado problema, podendo gerar novos conhecimentos.

Ao analisar as publicações dos anais do Simpósio Internacional Processo Civilizador', Souza (2009) concluiu que a maior parte das pesquisas seguem dizendo o que o próprio Elias escreveu, em detrimento da produção de novos conhecimentos à luz da teoria. Partindo dessas considerações, que são fixadas no tempo e no espaço, optouse pela realização de pesquisa análoga em um universo maior, visando identificar o estágio atual de apropriação da sociologia elisiana no Brasil. Para tanto, foram empregados os pressupostos metodológicos do Estado do Conhecimento aliados às considerações metodológicas da Análise de Conteúdo.

O diagnóstico do estágio de apropriação da teoria dos processos civilizadores no país é importante porque permite visualizar avanços, permanências e lacunas em sua adoção. Por sua vez, com base nesses dados, novas pesquisas poderão ser realizadas a partir de um elevado nível de síntese, contribuindo para um avanço nos próprios usos de Norbert Elias no Brasil.

\section{Procedimentos metodológicos}

Para alcançar o objetivo proposto optou-se pela orientação metodológica das pesquisas denominadas Estado do Conhecimento (EC). De acordo com Ferreira (2002, p. 258), as pesquisas sobre o EC são bibliográficas, descritivas, de caráter inventariante e objetivam mapear e discutir uma determinada produção acadêmica, "tentando responder que aspectos e dimensões vêm sendo destacados e privilegiados em diferentes épocas e lugares, de que formas e em que condições têm sido produzidas". Complementando este entendimento Teixeira (2006, p. 60) destacou que os resultados destes estudos subsidiam novas pesquisas e servem como "fonte de alimentação e retroalimentação do saber".

Esse tipo de pesquisa é desenvolvido em dois momentos interdependentes: no primeiro, ocorre a quantificação e a identificação dos dados bibliográficos, visando o mapeamento da publicação em dado período, local e área de produção; no segundo, o pesquisador deverá inventariar a produção, observando as escolhas teóricas e/ou metodológicas adotadas e os resultados obtidos (Ferreira, 2002). Assim, visando tais procedimentos, técnicas da Análise de Conteúdo $(\mathrm{AC})^{2}$ foram aliadas aos encaminhamentos das pesquisas de EC, a saber: pré-análise, exploração do material e tratamento dos resultados, inferências e interpretações.

$\mathrm{Na}$ pré-análise, fase que corresponde à organização do material empírico, foram escolhidos os documentos, elencados os objetivos e elaborados os indicadores que fundamentaram a análise. A constituição do conjunto documental atendeu aos seguintes critérios: a) acesso às produções a partir das bases de dados frequentemente utilizadas no Brasil - Scientific Eletronic Library Online (Scielo) e Portal de Periódicos CAPES/MEC ${ }^{3}$; b) artigos e ensaios escritos em língua portuguesa e publicados em

\footnotetext{
${ }^{1}$ Evento periódico onde são estabelecidos diálogos entre pesquisadores brasileiros e estrangeiros sobre a sociologia elisiana. Para a análise, Souza (2009) considerou as publicações até a XII edição.

${ }^{2} \mathrm{~A}$ análise de conteúdo pode ser definida como um conjunto de disposições metodológicas para a análise de comunicações. Sua principal finalidade é obter, "por procedimentos sistemáticos e objetivos de descrição do conteúdo das mensagens, indicadores (quantitativos ou não) que permitem a inferência de conhecimentos relativos às condições de produção/recepção (variáveis inferidas) destas mensagens" (BARDIN, 2011, p. 48).

${ }^{3}$ Busca realizada em 2019. Foi também efetuada uma consulta na base de dados Scopus, entretanto, não foram identificadas produções que adotaram a teoria dos processos civilizadores em análises empíricas de figurações brasileiras.
} 
revistas acadêmicas das Ciências Humanas e Sociais. Os indicadores para a consulta foram "processo civilizador", "Elias" e "Brasil". Ao todo, emergiram 08 produções na Scielo e 24 na CAPES/MEC.

Seguiu-se, então, para um segundo recorte documental: foram elencados para análise somente os artigos e ensaios publicados em língua portuguesa que trabalharam qualitativamente noções da teoria dos processos civilizadores aplicadas ao contexto brasileiro, ou seja, não foram consideradas para a análise as produções que fizeram referências isoladas à Norbert Elias. Assim, a composição do cojunto documental para a análise contou com a verificação de todos os títulos e inicialmente os resumos, por apresentarem os elementos essenciais de um trabalho de caráter científico ${ }^{4}$. Ao término dessa etapa, oito foram as produções selecionadas, entendidas aqui como representantes da forma como os pesquisadores brasileiros têm utilizado a teoria no desenvolvimento de pesquisas empíricas.

Após estes encaminhamentos metodológicos, seguiu-se para a exploração do material. Nessa etapa, os dados brutos foram sistematizados por meio da codificação. Com este procedimento, definiu-se como critério que as unidades de registro (UR) - o "segmento do conteúdo considerado unidade base, visando a categorização e a contagem frequencial" (BARDIN, 2011, p. 134) - seriam as temáticas emergentes mais frequentes. Após tal definição, seguiu-se para a terceira etapa da análise de conteúdo, onde foi realizada a categorização. Assim, foram elencados como referentes à análise os aspectos comuns entre os trabalhos, a saber: a) metodologia (recorte temporal e formas de comparação; b) aspectos teóricos e referenciais elisianos utilizados. Por fim, foram realizadas as inferências e interpretações.

\section{Resultados e discussões}

Visando atender ao objetivo proposto, foram analisadas as 08 produções acadêmicas emergentes dos procedimentos metodológicos acima descritos. Para a montagem dos quadros-resumos ${ }^{5}$, as produções foram classificadas em P1, P2 e assim sucessivamente até P8 e organizadas a partir dos seguintes parâmetros: autores, ano de publicação, revista, qualis e área temática/disciplina, vinculação institucional, estados e regiões geográficas das Universidades em que as pesquisas foram desenvolvidas.

Quadro 1 - Conjunto documental para a análise

\begin{tabular}{|c|c|}
\hline PRODUÇÃO & AUTORES \\
\hline P1 & OLIVEIRA, E.C (2003) \\
\hline P2 & XAVIER, N.R.; SARAT, M. (2012) \\
\hline P3 & PASSIANI, E. (2012) \\
\hline P4 & RABELO, G. (2013) \\
\hline P5 & AMORIM, S.S.; FERRONATO, C. (2013) \\
\hline P6 & GONÇALVES, S.C. (2013) \\
\hline P7 & PEREIRA, A.V.; ROTENBERG, L.; OLIVEIRA, S.S. (2013) \\
\hline P8 & CAMPOS, R.D. (2014) \\
\hline
\end{tabular}

Fonte: Autoria própria (2020).

O Quadro 1 permite observar que a partir de 2012 cresceu o número de estudos empíricos de abordagem elisiana indexados nas bases de dados consultadas. Todavia, o Quadro 2, que apresenta a vinculação institucional dos autores, bem como as regiões geográficas e os estados nas quais as universidades envolvidas estão situadas,

\footnotetext{
${ }^{4}$ Segundo Gil (1999: 187), em um resumo deve constar "uma apresentação concisa do conteúdo do trabalho, envolvendo: objetivo, métodos, principais resultados e conclusões".

${ }^{5}$ Expressão adotada por Teixeira (2006) quando da sistematização geral dos dados bibliográficos para posterior análise.
} 
demonstra que as produções que adotam tal referencial estão distribuídas de maneira heterogênea pelo país.

Quadro 2 - Vinculação regional e institucional dos pesquisadores

\begin{tabular}{|c|c|c|c|}
\hline PROD. & REGIÃO & ESTADO & UNIVERSIDADES ENVOLVIDAS \\
\hline P1 & Centro-Oeste & Goiás & Universidade Estadual de Goiás \\
\hline P2 & Centro-Oeste & Mato Grosso do Sul & Universidade Federal da Grande Dourados \\
\hline P3 & Sudeste & São Paulo & Faculdade de Campinas \\
\hline P4 & Sul & Santa Catarina & Universidade do Extremo Sul Catarinense \\
\hline P5 & Nordeste & Sergipe & Universidade Tiradentes \\
\hline P6 & Sudeste & São Paulo & Universidade Estadual Paulista \\
\hline P7 & Sudeste & Rio de Janeiro & Universidade Federal Fluminense e Fiocruz \\
\hline P8 & Sudeste & Minas Gerais & Universidade Federal de Uberlândia \\
\hline
\end{tabular}

Fonte: Autoria própria (2020).

A maioria dos artigos e ensaios publicados foram escritos por pesquisadores da região Sudeste (50\%). Acredita-se que esse percentual pode estar relacionado ao número de instituições de ensino superior situadas na referida região ${ }^{6}$, bem como ao Grupo Processos Civilizadores - iniciado em 1996 pela iniciativa da Faculdade de Educação Física da Universidade de Campinas, em São Paulo - que vem estimulado na região o desenvolvimento de pesquisas de perspectiva elisiana.

O Quadro 3 apresenta as revistas acadêmicas das Ciências Humanas e Sociais nas quais foram publicadas as pesquisas em questão, bem como sua área temática/disciplina:

Quadro 3 - Características elementares das revistas acadêmicas que publicaram sobre a noção de processo civilizador aplicada ao contexto brasileiro.

\begin{tabular}{|c|c|c|c|}
\hline PROD. & REVISTA & QUALIS & ÁREA TEMÁTICA/DISCIPLINA \\
\hline P1 & História, Ciências, Saúde - Manguinhos & A1 & História das Ciências e da Saúde \\
\hline P2 & Acta Scientiarum. Education & A2 & Educação \\
\hline P3 & Revista Sociedade e Estado & B2 & Ciências Sociais \\
\hline P4 & Hist. Educ. (Online) & A2 & História da Educação \\
\hline P5 & Educar em Revista & A1 & Educação \\
\hline P6 & OPSIS & B2 & História e Ciências Sociais \\
\hline P7 & História, Ciências, Saúde - Manguinhos & A1 & História das Ciências e da Saúde \\
\hline P8 & Revista Brasileira de História & A1 & História \\
\hline
\end{tabular}

Fonte: Autoria própria (2020).

É notável a predominância de publicações em revistas de História ou que adotam perspectiva histórica (62,5\%). Acredita-se que esse fenômeno pode estar relacionado com a própria postura de Elias em relação à História no desenvolvimento de sua teoria: em suas pesquisas, além do cuidado historiográfico necessário para a compreensão das especificidades sociais de cada figuração (CHARTIER, 2001), o sociólogo prezou pelo desenvolvimento de pesquisas empíricas, pautado em fontes - fossem elas manuais de boas maneiras (ELIAS, 1993 e 2011), observações realizadas em uma formação social determinada (ELIAS; SCOTSON, 2000) ou dados relativos às mortes na estrada no decorrer dos anos (ELIAS, 2006).

Apesar da destacada predileção das pesquisas de perspectiva histórica à teoria dos processos civilizadores, ao analisar o Quadro 3 é possível afirmar que são poucas as disciplinas das Ciências Humanas e Sociais que vêm adotando a sociologia elisiana como referencial teórico e metodológico de interpretação para os problemas de sua área. De

\footnotetext{
${ }^{6}$ De acordo com Mundo Vestibular, site especializado neste tipo de concurso, mais de $40 \%$ dos estudantes do ensino superior encontram-se na região Sudeste. Disponível em: http://www.mundovestibular.com.br/articles/17489/1/40-dos-estudantes-de-ensino-superior-sao-da-regiaosudeste/Paacutegina1.html. Acesso em: 18 jul. 2020.
} 
acordo com a Tabela de Áreas do Conhecimento, elaborada pela CAPES, tais ciências totalizam 25 disciplinas. No entanto, apenas três delas têm adotado as noções desenvolvidas por Elias como referencial em análises empíricas de formações brasileiras, a saber: Ciências Sociais, Educação e História.

Ainda sobre o Quadro 3, chama a atenção que os artigos e ensaios indexados nas bases pesquisadas foram publicados em revistas de maior qualificação, nas quais o processo editorial costuma ser mais minucioso. Como até recentemente inexistiam "pesquisas originais que tenham, de fato, matizado a teoria de Elias à realidade brasileira" (SOUZA, 2009, s/p), acredita-se que a inovação do uso da teoria dos processos civilizadores para análises empíricas de problemas nacionais tenham contribuído para a publicação nas revistas supracitadas.

Após a conclusão da primeira etapa do estado do conhecimento, na qual foi feita a apresentação sumária dos dados bibliográficos das produções, que possibilitaram conhecer o contexto científico no qual tais pesquisas foram desenvolvidas, seguiu-se para a análise dos aspectos teórico-metodológicos dos artigos e ensaios.

O artigo "A epidemia de varíola e o medo da vacina em Goiás" (P1) apresentou como objetivo a análise de dois aspectos referentes à varíola em Goiás: o aumento de surtos em consequência da modernização dos transportes e do crescimento demográfico e a resistência da população às medidas civilizadoras do Estado (vacinas). O recorte temporal de investigação abarcou o final século XIX e as três primeiras décadas do século XX. Para seu desenvolvimento foram utilizadas fontes bibliográficas e documentais (livros, relatórios da Província de Goiás e poemas). Em uma perspectiva hermenêutica, que considerou aspectos biológicos, históricos e, em especial, culturais. O autor utilizou a noção de civilização desenvolvida por Elias para demonstrar a especificidade de Goiás em relação à doença. Segundo Oliveira (2003: 942), "Goiás era uma das mais atrasadas províncias do Império, e a vacinação, um meio de mostrar sua inserção no processo civilizador". Apesar da resistência inicial da população à vacina antivariólica, a pesquisa demonstrou que as medidas sanitárias adotadas no Brasil e, neste caso, em Goiás foram utilizadas no sentido de instaurar atitudes e comportamentos "civilizados". As obras de Elias referenciadas por Oliveira e que respaldaram a análise teórica foram: A solidão dos moribundos e O processo civilizador (v.1).

O texto "Infância e educação civilizadora na literatura brasileira" (P2) objetivou apreender o processo de individualização da criança e sua inserção social a partir da educação formal em âmbito escolar e da informal realizada pela família. O recorte temporal estendeu-se entre o final do século XIX e início do XX e corresponde às memórias presentes nas obras literárias autobiográficas de José Lins do Rego (Menino do Engenho, publicado em 1932) e Graciliano Ramos (Infância, publicado em 1945). Neste artigo, as autoras, a partir de Elias, conceberam a escola - em interdependência com a família - como uma instituição de caráter civilizador, uma vez que impõem regras e contribuem à formação de uma segunda natureza nas crianças. Assim, a partir de representações literárias, Xavier e Sarat analisaram como se deu essa modelagem e concluíram que "o processo escolar impôs um novo ritmo à ludicidade dos meninos. (...) o tempo da criança foi instituído com outra significância e simbologia. Ela teve que aprender que existia outro tempo: o tempo escolar" (XAVIER; SARAT, 2012: 229). Este trabalho foi desenvolvido com base nas seguintes obras de Elias: O processo civilizador (v.1 e 2), A sociedade dos indivíduos, Sobre o tempo e A busca da excitação.

O ensaio intitulado "Não existe pecado abaixo do Equador? Algumas considerações sobre o processo de formação da sociedade de corte no Brasil (18081889)" (P3) parte da premissa levantada por Florestan Fernandes de que os países periféricos são ideais para testar o pensamento social produzido em centros como a Europa - desde que passem por revisões, correções e atualizações. Assim, trabalho levantou os principais conceitos desenvolvidos por Norbert Elias, visando indicar 
possíveis problemas que a teoria dos processos civilizadores enfrentaria se utilizada para estudar a formação da sociedade brasileira. O recorte temporal iniciou em 1808, com a chegada da família real ao Brasil e a implantação da sociedade de corte no país, e estendeu-se até 1889 (proclamação da República). Para o desenvolvimento da pesquisa, Passiani utilizou fontes bibliográficas que permitiram observar questões não contempladas por Elias, específicas do desenvolvimento histórico-social brasileiro, a saber: a fabricação de uma nobreza nativa; a ausência de uma burguesia definida, responsável pela disseminação dos padrões de conduta socialmente aceitáveis na corte joanina; e a presença de um regime escravocrata. A identificação desses elementos permitiu ao autor compreender que o processo civilizador no Brasil se manteve restrito aos círculos da corte, não havendo - diferentemente da Europa - um elemento social divulgador das atitudes tidas como "civilizadas", contribuindo para "uma estrutura social extremamente hierarquizada, violenta e excludente" (PASSIANI, 2012: 590). Para desenvolver suas considerações, o autor utilizou as seguintes referências elisianas: $O$ processo civilizador (v. 1 e 2), Verbete civilização ["Zivilisation"] para um léxico de sociologia e A sociedade de corte.

O artigo "O jornal escolar $O$ Estudante Orleanense: não podemos tornar as crianças felizes, mas podemos fazê-las felizes tornando-as boas (Santa Catarina, 19491973)" (P4) objetivou compreender a contribuição do jornal O Estudante Orleanense e da Associação Jornal Escolar O Estudante Orleanense para o processo civilizador em âmbito escolar. Para tanto, Rabelo utilizou como fontes jornais e atas das referidas instituições, produzidas entre 1949 e 1973, além da legislação de Santa Caratina sobre educação do período. Partindo das considerações de Elias sobre os processos civilizadores, 0 autor concebeu a escola como um instrumento de controle, onde a arquitetura, as associações auxiliares e, em especial, o jornal escolar funcionavam como mecanismos para a modulação de comportamentos. Para Rabelo (2013: 216), tais instituições contribuíram para "a naturalização de novos hábitos, costumes e boas maneiras que nada tinham de natural, mas que foram ditados pela elite republicana na tentativa de serem incorporados pelos sujeitos escolares, em especial as crianças". Em seus estudos o autor utilizou uma única obra de Elias: O processo civilizador (v.1).

No texto "O processo de profissionalização docente e a criação da Escola Normal em Sergipe (1827-1879)" (P5), buscando compreender como ocorreu a preparação dos professores de primeiras letras na província de Sergipe, Amorim e Ferronato estudaram a partir de Elias como se configurou a profissão docente e de que forma "se constituiu o habitus profissional pensado para o projeto de constituição de nação para o Brasil dentro de um processo civilizador" (AMORIM; FERRONATO, 2013: 209). Para tanto, os autores utilizaram como fonte a legislação educacional sobre essa etapa do ensino, entre os anos de 1827 e 1879. Tais leis delimitaram as atribuições dos professores na sociedade, além de definirem a conduta moral esperada desses profissionais. Os autores concluíram que, neste período, na província de Sergipe, houve um processo de civilização da conduta social, que perpassou pelo ambiente escolar primário, e que foi marcado por avanços e retrocessos, bem como por movimentos de resistência. Para o desenvolvimento da pesquisa, Amorim e Ferronato utilizaram dois livros de Elias: O processo civilizador (v. 1) e A sociedade de corte.

No ensaio denominado "Processo civilizador e colonização em Norbert Elias: uma teoria interpretativa através da Sociologia, da História e da Psicologia" (P6), Gonçalves (2013) realizou uma pesquisa na bibliografia elisiana sobre a relação entre a teoria dos processos civilizadores e o colonialismo, verificando a possibilidade de sua utilização em análises de formações e processos sociais brasileiros. Assim, ao estudar as considerações de Elias sobre a colonização como difusora da cultura "civilizada", considerou que é possível adotar a teoria desenvolvida pelo sociólogo alemão como "uma potencial ferramenta para analisar a realidade social de regiões que sofreram 0 
colonialismo europeu, como a América Latina e o Brasil, para compreender a dinâmica civilizatória que a Europa ocidental imprimiu nos territórios que colonizou" (GONÇALVES, 2013: 202). Após apresentar a síntese dos principais pontos que compõem a teoria elisiana e demonstrar, de maneira problematizada, as referências de Elias à expansão do comportamento civilizado da Europa às suas colônias, Gonçalves (2013) conclui que é possível adotar este referente analítico para a compreensão de aspectos sociogênicos e psicogênicos em regiões de passado colonial. Suas afirmações têm respaldo teórico nos seguintes trabalhos de Elias: A condição humana, A sociedade de corte, A sociedade dos indivíduos, Introdução à sociologia, O processo civilizador (v. 1 e 2), Os alemães, Os estabelecidos e os outsiders e A busca da excitação.

A produção intitulada "Relações de gênero e interdependências: reflexões a partir de mudanças na configuração hospitalar" (P7) analisou as mudanças na configuração hospitalar, com destaque para as relações de gênero, a partir das noções de figuração e interdependência. Nesse sentido, Pereira, Rotenberg e Oliveira (2013) conceberam a instituição hospitalar como uma figuração na qual existem relações de interdependência e, portanto, relações de poder entre seus profissionais. Segundo as autoras, "O resgate do pensamento de Elias nos auxilia no entendimento de que o poder não permanece em todas as dimensões nem em tempo integral apenas nas mãos de um determinado grupo" (PEREIRA; ROTENBERG; OLIVEIRA, 2013: 1021). Assim, ao estudar a dinâmica das relações de gênero nos hospitais a partir de fontes bibliográficas, as autoras concluíram que as oscilações no diferencial de poder, derivadas de embates decorrentes de divergências de interesses, resultaram em novas configurações no interior da instituição hospitalar. Para o desenvolvimento da pesquisa as autoras utilizaram os seguintes referenciais elisianos: Introdução à sociologia, Escritos e Ensaios I, O processo civilizador (v. 1 e 2), A sociedade dos indivíduos, The changing balance of power between the sexes. A process-sociological: the examples of the Ancient Roman State e Os estabelecidos e outsiders.

O artigo "Imprensa e educação feminina em zona pioneira: o caso do Noroeste Paulista (1920-1940)" (P8) discutiu a importância da imprensa regional para o ordenamento do Noroeste Paulista. Para tanto, foram utilizados como fonte periódicos publicados entre 1920 e 1940. Nesse período, os jornais visavam educar a população e, de acordo com Campos, a imprensa Araraquarense procurou "civilizar" os habitantes da região, em especial as mulheres. Para a autora, "as mulheres de variadas etnias, gerações e classes sociais se tornaram o público-alvo de um claro processo normatizador, perpetrado por uma miríade de poderes (...) que buscavam cotidianamente discipliná-las por intermédio de várias práticas: aconselhamentos, legislação, interdições, etc." (CAMPOS, 2014: 316). Recorrendo à teoria sociológica desenvolvida por Elias, Campos desenvolveu a noção de civilização para, após a análise das fontes jornalísticas, concluir que os impressos tiveram protagonismo no processo educativo daquela localidade, especialmente sobre o comportamento e o modo de ser das mulheres. Como referência, foram adotadas duas obras de Elias, a saber: O processo civilizador (v. 1 e 2) e Escritos e Ensaios I.

Em relação aos aspectos metodológicos, a análise das produções permitiu observar que os pesquisadores brasileiros têm adaptado a teoria dos processos civilizadores às figurações a serem analisadas. Essa questão é evidente especialmente em relação ao recorte temporal de análise. Em seus primeiros trabalhos, Elias advogou a importância de análises em longa duração e para desenvolver a teoria dos processos civilizadores analisou cerca de 700 anos do desenvolvimento de figurações europeias (ELIAS, 2011). No final de sua trajetória, o autor - apesar de não discutir sistematicamente a questão - abriu prerrogativa para pensar recortes médios quando trabalhou a autorregulação necessária aos motoristas ao longo de três décadas (ELIAS, 2006). 
No caso dos pesquisadores brasileiro, a baliza temporal média, calculada com base nas produções analisadas, é de aproximadamente 50 anos, sendo que o menor recorte abrange 20 anos e o mais longo 81 anos. A adoção de um recorte temporal comparativamente inferior às formulações originais demonstra que as pesquisas aqui analisadas se encontram em um estágio mais avançado de apropriação da teoria em comparação aos achados de Souza (2009), uma vez que se respaldam em Elias e avançam, atendendo às especificidades de seus objetos.

A opção por recortes médios justifica-se em razão de: a) a análise está centrada em um momento específico do desenvolvimento sócio-histórico da figuração estudada, como é o caso do artigo "Infância e educação civilizadora na literatura brasileira" (P2), que se debruçou sobre o processo de individualização da criança pela escola e pela família em um período específico, estabelecido a partir das fontes consultadas; b) a análise acompanha o desenvolvimento de certo processo em uma figuração específica desde o início até um recorte determinado (seu fim ou uma data cujo valor seja justificável). Nessa perspectiva temporal, entre outros exemplos, é possível citar a análise de epidemias (P1) ou de projetos empreendidos por jornais periódicos (P4 e P8).

Em relação ao método comparativo, em seus trabalhos Elias contrastou: a) diferentes figurações ao longo do tempo; b) processos sociais de espaços distintos; c) o desenvolvimento de uma mesma figuração no decurso no tempo. No caso das produções analisadas, foi possível observar que os pesquisadores têm se valido de comparações de uma figuração consigo mesma no decorrer do tempo, analisando os processos que a tornaram mais ou menos civilizada. Infere-se que essa opção metodológica tem relação com as limitações impostas pelo próprio processo de desenvolvimento heterogêneo do Brasil, aliada às dificuldades de tempo e orçamento para pesquisas comparativas em formações sociais distantes geograficamente.

Sobre os aspectos teóricos, com exceção das produções P3 e P6, em maior ou menor medida, os trabalhos apenas aplicaram as noções da sociologia elisiana, como habitus, figuração, individualização e interdependência, em detrimento de problematizalas às especificidades do objeto investigado. Neste ponto, os achados coadunam com a análise realizada por Souza (2009: $\mathrm{s} / \mathrm{p}$ ): "ainda que compreendamos os marcos conceituais de Elias, faltará o mergulho em nosso próprio habitus", ou seja, um conhecimento aprofundado do objeto de investigação em questão, que permita perspectiva-lo à luz da teoria dos processos civilizadores - não o reduzindo à teoria.

Por fim, em relação às referências adotadas, há artigos que utilizaram uma ou duas referências de Elias, com destaque para $O$ Processo Civilizador (v. 1 e 2); outros se pautaram em mais de cinco livros para desenvolver suas pesquisas. Apesar dos elementos fundamentais da teoria dos processos civilizadores encontrarem-se nos dois tomos de O Processo Civilizador, Elias seguiu publicando a partir dessa matriz teórica. No desenvolvimento de seus trabalhos, o autor retomou alguns pontos, esclareceu outros e seguiu lapidando sua proposição até o fim de seus dias. Como exemplo é possível citar a noção de descivilização, aprofundada pelo autor à medida que seus críticos imputaram um caráter evolucionista à teoria elisiana. Assim, considerando o contínuo desenvolvimento teórico de Elias, percebeu-se uma lacuna na utilização de obras para além das publicações iniciais. Embora a maioria dos escritos do autor estejam em alemão e/ou em inglês, conhecer a fundo a bibliografia elisiana em português é fundamental para a compreensão de conceitos revisitados pelo sociólogo no decurso de sua trajetória intelectual.

\section{Conclusões}

O mapeamento e a análise das produções indexadas nas bases de dados Scielo e Portal de Periódicos CAPES/MEC que estudaram empiricamente questões brasileiras a 
partir da teoria dos processos civilizadores, permitiram inferir que a partir de 2012, aumentou o número de pesquisas com essa temática - em sua maioria realizadas em instituições de ensino superior da região Sudeste e publicadas em revistas acadêmicas qualificadas, de perspectiva histórica.

Em um apanhado geral, apesar do reduzido número de estudos empíricos de figurações brasileiras que se valeram da teoria dos processos civilizadores como referencial teórico e metodológico, é possível afirmar que a forma como os pesquisadores têm adotado a teoria demonstra avanços, no sentido de uma emancipação metodológica em relação ao recorte temporal. Sobre formas de utilização do método comparativo, dada a heterogeneidade da história e da disseminação dos costumes no Brasil, estas encontram-se ainda restritas à análise de uma única formação. Para a realização de comparações em maior dimensão faz-se necessário um trabalho em rede, visando a compreensão das diferentes realidades nacionais.

Em relação à adequação da teoria aos objetos estudados, as produções analisadas demonstraram que ainda é preciso avançar. Apenas duas pesquisas fizeram um exercício de adaptação da teoria às demandas da realidade empírica investigada. Acredita-se que a explicação para esse fenômeno seja decorrente do conhecimento elementar da obra de Elias por parte de alguns pesquisadores. Por mais que os principais elementos da teoria estejam concentrados nos dois tomos de $O$ Processo Civilizador, esta seguiu sendo desenvolvida ao longo de toda a trajetória intelectual de Elias. Sendo assim, para discussões mais aprofundadas é imprescindível o conhecimento das obras do autor para além deste clássico.

Com base no exposto é possível afirmar que, apesar dos avanços metodológicos apresentados, a utilização dos conceitos teóricos elaborados por Elias por vezes ainda ocorre de maneira literal. Nesse sentido, entende-se que a apropriação brasileira da sociologia elisiana encontra-se em uma posição intermediária, situada entre o segundo e o terceiro estágio apontados por Souza (2009), ou seja, entre a citação literal e a construção de novos saberes. Que o diagnóstico aqui apresentado estimule novas pesquisas com base nesta teoria, não pelo recurso à citação literal, mas por perspectivala como uma lente na interpretação de diferentes aspectos dos processos civilizadores brasileiros em suas especificidades.

\section{Referências}

AMORIM, S. S.; FERRONATO, C. O processo de profissionalização docente e a criação da Escola Normal em Sergipe (1827-1879). Educ. rev. [online]., n. 49, p. 209-225, jul./set. 2013. Disponível em: http://www.scielo.br/pdf/er/n49/a12n49.pdf. Acesso em: 18 jul. 2020.

BARDIN, L. Análise de conteúdo. São Paulo: Edições 70, 2011.

CAMPOS, R. D. Imprensa e educação feminina em zona pioneira: o caso do Noroeste Paulista (1920-1940). Rev. Bras. Hist. [online], v. 34, n. 67, p. 309-322, 2014. Disponível em: http://www.scielo.br/pdf/rbh/v34n67/a14v34n67.pdf. Acesso em: 18 jul. 2020.

CHARTIER, R. Prefácio. In: ELIAS, N. A sociedade de Corte. Rio de Janeiro: Zahar, 2001.

ELIAS, N. O processo civilizador: formação do Estado e civilização. Rio de Janeiro: Zahar, 1993.

2011.

O processo civilizador: uma história dos costumes. Rio de Janeiro: Zahar, 
Escritos \& ensaios. Vol. 1: Estado, processo, opinião pública. Rio de Janeiro, Jorge Zahar, 2006.

Norbert Elias por ele mesmo. Rio de Janeiro: Jorge Zahar Ed., 2001.

; SCOTSON, J. L. Os estabelecidos e os outsiders: sociologia das relações de poder a partir de uma pequena comunidade. Rio de Janeiro: Jorge Zahar Ed., 2000.

FERREIRA, N. S. A. As pesquisas denominadas "Estado da Arte". Educação \& Sociedade, v. 23 , n. 79 , p. 257-272, ago. 2002. Disponível em: http://www.scielo.br/pdf/es/v23n79/10857.pdf. Acesso em: Acesso em: 18 jul. 2020.

FUNDAÇÃO COORDENAÇÃO DE APERFEIÇOAMENTO DE PESSOAL DE NÍVEL SUPERIOR. Tabela Áreas do Conhecimento. 2017. Disponível em: http://www.capes.gov.br/images/documentos/documentos_diversos_2017/TabelaAreasCo nhecimento_072012_atualizada_2017_v2.pdf. Acesso em: 18 jul. 2020.

GEBARA, A. Norbert Elias no Brasil. In: GEBARA, A.; COSTA, C. J.; SARAT, M. Leituras de Norbert Elias: processo civilizador, educação e fronteiras. Maringá: Eduem, 2014.

GIL, A. C. Métodos e técnicas de pesquisa social. 5. ed. São Paulo: Atlas, 1999.

GONÇALVES, S. C. Processo civilizador e colonização em Norbert Elias: uma teoria interpretativa através da sociologia, da história e da psicologia. Revista OPSIS, v. 13, n. 1 , p. 200-221, jan./jun. 2013. Disponível em: https://www.revistas.ufg.br/Opsis/article/view/19011/15182\#.WIvPUKinHIU. Acesso em: 18 jul. 2020.

MORAIS E SILVA, M.; CAPRARO, A. M.; SOUZA, J.; MARCHI JUNIOR, W. Norbert Elias e Michael Foucault - apontamento para uma tematização relacional da noção de poder. R. Inter. Interdisc. INTERthesis, v.11, n.1, p. 254-275, jan./jun. 2014. Disponível em: https://periodicos.ufsc.br/index.php/interthesis/article/view/1807-

1384.2014v11n1p254/26895. Acesso em: 18 jul. 2020.

MUNDO VESTIBULAR. $40 \%$ dos estudantes de ensino superior são da região sudeste. Disponível em: http://www.mundovestibular.com.br/articles/17489/1/40-dosestudantes-de-ensino-superior-sao-da-regiao-sudeste/Paacutegina1.html. Acesso em: 18 jul. 2020.

NORBERT ELIAS FOUNDATION. People. Disponível em: http://norbert-elias.com/aboutelias-foundation/elias-community-worldwide/. Acesso em: 18 jul. 2020.

OLIVEIRA, E. C. de. A epidemia de varíola e o medo da vacina em Goiás. Hist. Cienc. Saúde-Manguinhos [online], v. 20, n. 3, p. 939-962, jul./set. 2003. Disponível em: http://www.scielo.br/pdf/hcsm/v20n3/0104-5970-hcsm-20-03-0939.pdf. Acesso em: 18 jul. 2020.

PASSIANI, E. Não existe pecado abaixo do Equador? Algumas considerações sobre o processo de formação da sociedade de corte no Brasil. Soc. estado. [online], v. 27, n. 3, p. 571-593, set./dez. 2012. Disponível em: http://www.scielo.br/pdf/se/v27n3/07.pdf. Acesso em: 18 jul. 2020.

PEREIRA, A. V; ROTENBERG, L.; OLIVEIRA, S. S. Relações de gênero e interdependências: reflexões a partir de mudanças na configuração hospitalar. Hist. 
cienc. Saúde-Manguinhos [online], v. 20, n. 3, p. 1007-1024, jul./set. 2013. Disponível em: http://www.scielo.br/pdf/hcsm/v20n3/0104-5970-hcsm-S010459702013005000009.pdf. Acesso em: 18 jul. 2020.

QUINTANEIRO, T. Processo civilizador, sociedade e indivíduo na teoria sociológica de Norbert Elias. Belo Horizonte: Argvmentvm, 2010.

RABELO, G. O jornal escolar $O$ Estudante Orleanense: não podemos tornar as crianças felizes, mas podemos fazê-las felizes tornando-as boas (Santa Catarina, 1949-1973). Hist. Educ. [online], v. 17, n. 40, p. 197-219, mai./ago. 2013. Disponível em: http://www.scielo.br/pdf/heduc/v17n40/v17n40a10.pdf. Acesso em: 18 jul. 2020.

ROJAS, C. A. A. Norbert Elias: historiador y crítico de la modernidad. Diálogos, DHI/UEM, v. 2, n. 1, p. 1-27, 1998. Disponível em: http://periodicos.uem.br/ojs/index.php/Dialogos/article/view/37478. Acesso em: 18 jul. 2020.

SOUZA, E. F. Norbert Elias: uma teoria desconectada à realidade brasileira - balançando o chicote. In: XII SIMPÓSIO INTERNACIONAL PROCESSO CIVILIZADOR, Recife, 2009. Anais... Recife: UFPE, 2009. Disponível em: http://www.uel.br/grupoestudo/processoscivilizadores/portugues/sitesanais/anais12/artigos/pdfs/mesas_redondas /MR_Souza.pdf. Acesso em: 18 jul. 2020.

TEIXEIRA, C. R. O "Estado da Arte": a concepção de avaliação educacional veiculada na produção acadêmica do Programa de Pós-Graduação em Educação: Currículo (19752000). Cadernos de Pós-Graduação - educação, São Paulo, v. 5, n. 1, p. 59-66, 2006. Disponível em: https://periodicos. uninove.br/index.php?journal=cadernosdepos\&page=article\&op=view\&p ath\%5B\%5D=1845\&path\%5B\%5D=1444. Acesso em: 18 jul. 2020.

XAVIER, N. R.; SARAT, M. Infância e educação civilizadora na literatura brasileira. Acta Scientiarum Education, v. 34, n. 2, jul./dez. 2012. Disponível em: http://periodicos.uem.br/ojs/index.php/ActaSciEduc/article/view/16168/9985. Acesso em: 18 jul. 2020. 